\title{
Evaluation of the Biological Control Agent's Efficiency Against the Causal Agent of Early Blight of Solanum melongena
}

\author{
Abdulnabi Abbdul Ameer Matrood ${ }^{1}$, Abdelhak Rhouma ${ }^{2}$ and Okon Godwin Okon ${ }^{3}$ \\ (1) Department of Plant Protection, College of Agriculture, University of Basra, Iraq; \\ (2) Higher Agronomic Institute of Chott Mariem Sousse, University of Sousse, Tunisia, Email: abdelhak.rhouma@ gmail.com; \\ (3) Department of Botany, Faculty of Biological Sciences, Akwa Ibom State University, Nigeria.
}

\begin{abstract}
Matrood, A.A.A., A. Rhouma and O.G. Okon. 2021. Evaluation of the Biological Control Agent's Efficiency Against the Causal Agent of Early Blight of Solanum melongena. Arab Journal of Plant Protection, 39(3): $204-209$. https://doi.org/10.22268/AJPP-039.3.204209

Eggplant, an important vegetable crop in Iraq, faces yield losses due to early blight disease caused by Alternaria solani. Two antagonistic fungi (Aspergillus niger and Purpureocillium lilacinum) isolated from eggplant rhizosphere were tested in vitro (dual confrontation technique) and in vivo (preventive treatments) as potential bioagents against the most virulent $A$. solani isolates. A. niger and $P$. lilacinum at $30 \%$ conidia/ml exhibited high inhibitory rate $(55.11 \%)$ against $A$. solani mycelial growth. Furthermore, these two antagonistic species when applied preventively at $30 \%$ of the stock conidial suspension in vivo, reduced significantly disease severity index (<28.41\%). Moreover, A. niger (11.98 units/g of soluble protein) and P. lilacinum (8.11 units/g of soluble protein) enhanced the polyphenol oxidase activity. Based on the results obtained by this study, it appears that $A$. niger and $P$. lilacinum could be employed as foliar treatments against $A$. solani to promote eggplant growth and development and induce plant systemic resistance. To control $A$. solani, it is encouraged to use natural enemies as components in integrated disease management.
\end{abstract}

Keywords: Alternaria solani, biological control, polyphenol oxidase, Solanum melongena, antagonistic fungi.

\section{Introduction}

Eggplant (Solanum melongena L.) belongs to the family Solanaceae, it is an important vegetable crop and it is among the most important vegetable crops. S. melongena has high nutritive values, rich in proteins, carbohydrates, fats, minerals and vitamins. Eggplant contributes quite a bit in the agricultural economy of Iraq. Recently, it is produced throughout the year in greenhouses (off season and early crops) as well as in the field (seasonal culture). The eggplant annual production in Iraq was reported to be around 102,452 thousand tons with an average of 12,261 $\mathrm{kg} / \mathrm{ha}$ (Saeed Omar \& Mohammed, 2020).

In Iraq, the eggplant crop is being affected by several diseases, amongst them is early blight caused by Alternaria solani. This pathogen causes severe damage to plant parts such as stems, leaves, fruits and stalks leading to serious yield losses. Worldwide annual economic yield losses due to early blight have been estimated around $35-78 \%$ decrease in yield. Early blight disease can occur and survive over a varied range of certain climatic conditions but it is most dominant in areas with high rainfall, dew and very high relative humidity (El-Debaiky, 2018; Matrood \& Rhouma, 2021a).

The most appropriate strategy used to control this Ascomycota is by methods that reduce spores' density (ElDebaiky, 2018). Control of A. solani is currently based on integrating different approaches. Unfortunately, the most common strategy employed to manage early blight by Iraqi farmers is through the application of fungicides. Around $\$ 32-\$ 45$ million is spent annually on fungicides worldwide

https://doi.org/10.22268/AJPP-039.3.204209

(C) 2021 Arab Society for Plant Protection الجمعية العربية لوقاية النبات to control Alternaria sp. (El-Tanany et al., 2018). Nevertheless, this approach caused human health hazards and increased environmental pollution. Therefore, alternative strategies to control this disease is needed. Biological control is the best alternative and eco-friendly approach for this purpose, and it is defined as total or partial destruction of $A$. solani spores by naturally occurring other organisms (Atia, 2005; Esh et al., 2010; Rhouma et al., 2016, 2018; Taghian et al., 2008). Many genera of antagonistic fungi such as; Trichoderma spp., Penicillium spp., Aspergillus spp. and Purpureocillium spp. proved to have high efficacy against early blight when tested under in vitro and in vivo conditions (El-Debaiky, 2018; Fontenelle et al., 2011; Leelasuphakul et al., 2008). D'Souza \& Devaraj (2011), Ramamoorthy et al. (2002), and El-Tanany et al. (2018) revealed that efficacy of these biological control agents (BCA's) also induced plant defence mechanisms.

The objectives of this investigation were to: (i) evaluate the pathogenicity of some A. solani isolates under greenhouse condition, (ii) isolate and identify antagonistic fungi from eggplant rhizosphere samples, and (iii) screen certain soil-borne fungal antagonist's for their abilities to reduce $A$. solani growth under in vitro and in vivo conditions.

\section{Materials and Methods}

Eggplant sample collection and Alternaria solani isolation

Eggplant leaves were collected from three greenhouses (9 $\mathrm{m} \times 60 \mathrm{~m}$ ) located in Basra Iraq (Hartha, Safwan and Fayhaa). Diseased plants samples showing typical symptoms of early blight caused by $A$. solani were 
collected. Eggplant small leaf pieces $(0.5-1 \mathrm{~cm})$ were sterilized by soaking in $3 \%$ solution of sodium hypochlorite $(\mathrm{NaOCl})$ for 2 min and washed three times with sterilized distilled water. The samples were dried and placed on the surface of Petri dishes $(9 \mathrm{~cm}$ in diameter) containing potato dextrose agar (PDA) medium amended with streptomycin $(60 \mu \mathrm{g} / \mathrm{ml})$. In each Petri dish, seven fragments were placed (total of 30 Petri dishes). The plates were incubated in the dark at $25 \pm 2^{\circ} \mathrm{C}$ for 5-7 days, and then examined to identify fungal colonies. The fungal species identification was carried by observing the macroscopic (growth, color, aspect of the colony) and microscopic characteristics (mycelium, conidiophore, conidia, resistance structures, sexual form), after a series of sub-culturing until purification of the fungus. The fungal species were identified using the blue cotton as a mounting liquid and by using different reference identification keys.

\section{Pathogenicity of Alternaria solani isolates}

This experiment was carried out in the greenhouse and concerned only with eggplant (cv. Barcelona) plants. The seeds were placed on the surface of Petri dishes $(9 \mathrm{~cm}$ in diameter) containing cotton balls soaked in sterilized distilled water. In each Petri dish, 25 seeds were placed (with total of 30 Petri dishes). Germinated eggplant seeds were placed in a pot $(50 \mathrm{~cm}$ in diameter $)$ containing a mixture of peat and vermiculite (1:1) which was autoclaved twice at $120^{\circ} \mathrm{C}$. The assay was carried out by spraying the eggplant leaves of each seedling ( 15 days old) by the same amount $(10 \mathrm{ml})$ of conidial suspension $\left(10^{6} \mathrm{cfu} / \mathrm{ml}\right)$ of each A. solani isolate. The plants were covered with a transparent plastic to ensure high humidity of $70-90 \%$ during 3 days after inoculation to ensure infection. A negative control was used by inoculating eggplant plants with sterilized distilled water (negative control). The pots were then placed in a greenhouse for 15 days. The experimental design was a randomized complete block design (RCBD) with 10 plants per replicate (3 replicates), and the entire experiment was repeated three times (Boughalleb-M'Hamdi et al., 2018). Different parameters were evaluated 15 days after inoculation. To measure the disease index for the different treatments, the following 0-4 scale was used (Mostafa et al., 2013): $0=$ no lesions; $1=$ lesions covering about $1-10 \%$ of the leaf surface; $2=$ lesions covering about $11-25 \%$ of the leaf surface; $3=$ lesions covering about $26-50 \%$ of the leaf surface; $4=$ lesions covering about $51-100 \%$ of the leaf surface. The severity data were processed by McKinney's formula, which generates a numeric disease severity index (DSI): DSI $(\%)=(\Sigma \mathrm{vn}) /(\mathrm{NV}) \times 100$, where $\mathrm{v}$ represents the numeric value of the disease index scale, $n$ is the number of plants assigned to the disease index scale, $\mathrm{N}$ is the total number of the plants and $\mathrm{V}$ is the numeric value of the highest disease index scale (Rhouma et al., 2018).

\section{Fungal community in eggplant rhizosphere}

Soil samples were collected from the same locations in Basra Iraq (Harth, Safwan and Al-Faiha) cultivated with eggplants. Soil samples were taken using a 7-cm-diameter soil auger from the rhizosphere of eggplant randomly in a zigzag fashion at $15 \mathrm{~cm}$ depth, and each sample was composited by ninety soil cores for each greenhouse. For each greenhouse, samples were mixed together into a single one. Nine soil samples (200 g) per replicate (3 replicates) were collected from each greenhouse (Rhouma et al., 2019). Samples were collected in sterile polythene bags and brought to the laboratory to isolate and identify fungal communities in different greenhouses. The isolation of soilborne fungi was determined by the dilution-plate method according to Boughalleb-M'Hamdi et al. (2017). $10 \mathrm{~g}$ of soil was diluted in $90 \mathrm{ml}$ sterile distilled water. Serial dilutions were made from $10^{-1}$ to $10^{-7}$. A volume of $0.1 \mathrm{ml}$ of each dilution was transferred aseptically into Petri dishes containing MEA (Malt extract agar). The plates were incubated in the dark at $25^{\circ} \mathrm{C}$ for 3 days. The fungal species identification was carried out by observing the macroscopic and microscopic characteristics, after a series of sub culturing until purification of the fungus, using cotton blue as a mounting liquid and by using different reference identification keys.

\section{In vitro and in vivo antagonism potential of fungal bioagents against pathogenic Alternaria solani}

Two antagonistic fungi isolated from eggplant rhizosphere were used in this study. For routine use, Purpureocillium lilacinus and Aspergillus niger were grown on potato dextrose agar (PDA) and conidia filtrate were prepared as described by Rhouma et al. (2018). The two fungal species were routinely grown on Sabouraud dextrose yeast agar at $25 \pm 1^{\circ} \mathrm{C}$ under a 16 -h light photoperiod, separately. Conidia were harvested from 7-days-old cultures by adding $10 \mathrm{ml}$ of sterilized distilled water supplemented with $0.02 \%$ Tween80. The conidial suspension was filtered through 2 layers of sterile muslin into a sterile $25 \mathrm{ml}$ plastic universal bottle and then agitated for 5 min using a horizontal shaker with $40 \mathrm{~mm}$ horizontal movement and 300 oscillations per min (conidia stock suspension). The conidial stock suspension was prepared in different dilutions $(10,20,30 \%)$ using sterilized distilled water. Conidial viability was evaluated for each batch and only lots found to be $>95 \%$ viable were used in this study.

The in vitro antifungal activities of the two fungal antagonists ( $P$. lilacinus and A. niger) on radial mycelial growth of $A$. solani were determined by the dual confrontation technique on PDA according to Matrood \& Rhouma (2021b). A volume of $100 \mu \mathrm{l}$ with different conidia filtrate concentrations $(10,20$ and $30 \%$ conidia/ml $)$ for each antagonistic fungus was transferred aseptically into Petri dishes containing PDA. One disc plug $(0.5 \mathrm{~cm})$ of pathogen (4-days-old culture) was placed separately on a single PDA plate $(9 \mathrm{~cm})$ in the same Petri dishes containing different conidia filtrate concentrations of each antagonistic fungus. The pathogen plug was placed in the center of the plate. A plug of pathogen was used as control treatment (without conidia filtrate of antagonistic fungus). Three replicates (five plates/replicate) for each individual treatment were conducted and the Petri dishes were incubated at $25 \pm 2^{\circ} \mathrm{C}$ for 5 days. The inhibition percent of pathogen radial mycelial growth (I) was assessed according to the formula of Rhouma et al. $(2018)$ : I $(\%)=\left(1-C_{n} / C_{0}\right) x$ 100; where: $C_{n}$ represents the diameter of pathogen radial growth in the presence of the indicated conidia filtrate 
concentrations of antagonist, whereas, $\mathrm{C}_{0}$ represents the diameter of pathogen radial growth in the control treatment.

The in vivo experiment was concerned only with preventive treatments. Eggplant (cv. Barcelona) leaves were sterilized by soaking them in $3 \%$ solution of sodium hypochlorite $(\mathrm{NaOCl})$ for $2 \mathrm{~min}$ and washed three times with sterilized distilled water. The preventive assay was carried out by spraying leaves of eggplant $(10 \mathrm{ml})$ with indicated concentrations of conidia filtrate $(10,20$ and $30 \%$ conidia/ml) separately for each antagonistic fungus. $10 \mathrm{ml}$ $\left(10^{6} \mathrm{cfu} \backslash \mathrm{ml}\right)$ of $A$. solani (the most virulent isolate isolated from Hartha) was applied 7 days later. Two controls were used; one by inoculating the leaves with the pathogen only (positive control), while the other with sterilized distilled water (negative control). The treated eggplant leaves were placed on the surface of Petri dishes $(9 \mathrm{~cm})$. Four leaves were placed per plate, with a total of 10 Petri dishes for each replicate, with three replications. The experimental design used was RCBD, and the entire experiment was repeated twice. The plates were incubated in the dark at $25 \pm 2{ }^{\circ} \mathrm{C}$ for 10 days, and then examined for disease severity index (DSI) (Matrood et al., 2021; Rhouma et al., 2018). Polyphenol oxidase activity (units/g of soluble protein) was determined by the method described by D'Souza \& Devaraj (2011) and measured only for the eggplant leaves treated with $30 \%$ conidia/ml (10 days after inoculation) at $420 \mathrm{~nm}$ wavelength.

\section{Statistical analysis}

The data were analyzed by ANOVA using SPSS version 20.0 statistical software (SPSS, SAS Institute, USA), to evaluate parameter values differences. Differences between treatments were determined by least significant difference (LSD) test at $\mathrm{P}=0.05$.

\section{Results and Discussion}

\section{Pathogenicity of Alternaria solani isolates}

A. solani isolates exhibited high degree of pathogenicity according to the measured disease severity index (DSI) parameter. All A. solani isolates were virulent with DSI values varying from 59.08 (A. solani isolated from Safwan) and $71.97 \%$ (A. solani isolated from Hartha) (control $=0 \%$ ) (Table 1). Symptoms initially appeared on the leaves in the form of small yellow spots as concentric rings then turned brown surrounded by a halo, and spots coalesce with time. These results are in agreement with previous investigations reported by Singh et al. (2017). Typical symptoms of $A$. solani to those produced in natural field conditions were observed on many inoculated plants (Alsafadi et al., 2012; Matrood et al., 2020; Poly \& Srikanta, 2013).

\section{Fungal community in the eggplant rhizosphere}

The identification of fungal species recorded in different samples rhizosphere soil samples collected from three experimental fields cultivated with eggplant are presented in Table 2. Data obtained showed that Aspergillus spp. were the most frequent (isolated from three greenhouses located in Basra), followed by Penicillium spp. and Mucor spp. However, the lowest frequency was found for Alternaria spp. The prevalence of Aspergillus and Penicillium spp. in the soil samples was consistent with what has been reported by Boughalleb-M'Hamdi et al. (2017), Gaddeyya et al. (2012), and Onyimba et al. (2014). De Lucca (2007) pointed out that variation in fungal species diversity and conidia dispersion was attributed to various factors (wind, relative humidity, moisture, temperature and air pollution) and varied from one season to another.

Table 1. Pathogenicity of $A$. solani isolates collected from different locations in Iraq.

\begin{tabular}{lc}
\hline Treatments & Disease severity index (\%) \\
\hline Negative control & $0.00 \mathrm{~d}$ \\
A. solani (Hartha) & $71.97 \mathrm{a}$ \\
A. solani (Safwan) & $59.08 \mathrm{c}$ \\
A. solani (Fayhaa) & $64.50 \mathrm{~b}$ \\
\hline Values followed by the same letters are not significantly different \\
at $\mathrm{P}=0.01$
\end{tabular}

Table 2. Fungal isolates obtained from eggplant rhizosphere collected from different locations in Iraq.

\begin{tabular}{ll}
\hline Locations & Fungal isolates \\
\hline Hartha & Aspergillus niger \\
& Fusarium spp. \\
& Penicillium spp. \\
& A. flavus \\
& A. niger \\
Safwan & Alavus \\
& Purpureocillium lilacinus \\
& Fusarium spp. \\
Fayhaa & Penicillium spp. \\
& A. niger \\
& Alternaria $\mathrm{spp}$. \\
& Mucor spp. \\
& P. lilacinum \\
\hline
\end{tabular}

In vitro and in vivo antifungal potential of fungal bioagents against Alternaria solani

The two antagonistic fungal species at different conidia concentrations exerted high significant reduction $(\mathrm{P}<0.01)$ on radial mycelial growth of $A$. solani, five days after incubation. Statistical analysis revealed high significant interactions between $A$. solani and the conidia filtrate concentrations of antagonists $(\mathrm{P}<0.01)$. The linear decrease of growth of the pathogenic fungi ranged from 63.66 (A. niger at $30 \%$ concentration of the stock conidial suspension) to $17.0 \%$ ( $P$. lilacinum at $10 \%$ of stock conidial concentration). A. niger showed a good ability to limit the mycelial growth of $A$. solani in vitro. In fact, the mycelial growth decreased in presence of $A$. niger with values of 63.66 and $40.86 \%$ at 30 and $20 \%$ concentration, respectively. In the same sense, in vitro assay revealed that $P$. lilacinum possessed a good antifungal potency with mycelial inhibition rate of $55.11 \%$ at $30 \%$ of stock conidial concentration (Table 3 ). 
The effect of four treatments on the disease severity index under in vivo conditions is shown in Table 4. Statistical analysis showed significant differences between the treatments $(\mathrm{P}<0.01)$. All treatments with different conidia filtrate concentrations decreased significantly the disease severity index (DSI) as compared with the positive control (DSI Mean $=53.11 \%)$. Results showed that $A$. niger $($ DSI Mean $=33.69 \%)$ and $P$. lilacinum $($ DSI Mean $=$ $31.15 \%$ ) were found effective to reduce the disease severity index. Among the treatments with the different conidia filtrate concentrations of the two fungal antagonists, $P$. lilacinum at $20 \%$ of stock conidial concentration (DSI = $18.61 \%$ ) exhibited significant DSI reduction in eggplant leaves followed by the $30 \%$ concentration of $A$. niger (DSI= $28.41 \%$ ) (Table 4).

Table 3. Effect of direct confrontation of two fungal antagonists (Aspergillus niger and Purpureocillium lilacinum) on mycelial growth inhibition of Alternaria solani five days after incubation at $25^{\circ} \mathrm{C}$.

\begin{tabular}{lcccc}
\hline & \multicolumn{2}{c}{\begin{tabular}{c} 
Mycelial growth inhibition rate (\%) \\
\cline { 2 - 4 } Fungal
\end{tabular}} & \multicolumn{3}{c}{$\begin{array}{c}\text { Dilutions of stock conidial } \\
\text { suspension (\%) }\end{array}$} & \\
\cline { 2 - 4 } antagonists & $\mathbf{1 0}$ & $\mathbf{2 0}$ & $\mathbf{3 0}$ & Mean \\
\hline A. niger & $29.17 \mathrm{aC}$ & $40.86 \mathrm{~B}$ & $63.66 \mathrm{aA}$ & 44.56 \\
$P$. lilacinum & $17.01 \mathrm{bC}$ & $42.96 \mathrm{~B}$ & $55.11 \mathrm{bA}$ & 38.36 \\
Mean & 23.09 & 41.91 & 48.79 & \\
\hline
\end{tabular}

Values followed by the same capital letters in the same row $(\mathrm{P}=0.01)$ or small letters in the same column $(\mathrm{P}=0.05)$ are not significantly different.

Table 4. The effect on eggplant leaves treated with fungal antagonists as measured by disease severity index.

\begin{tabular}{lcccc}
\hline & \multicolumn{3}{c}{ Disease severity index (\%) } & \\
\cline { 2 - 4 } Treatments & \multicolumn{3}{c}{$\begin{array}{c}\text { Dilutions of stock conidial } \\
\text { suspension (\%) }\end{array}$} & \\
\cline { 2 - 4 } Mean \\
\hline Positive control & $\mathbf{1 0}$ & $\mathbf{2 0}$ & $\mathbf{3 0}$ & \\
Negative control & $0.98 \mathrm{aA}$ & $49.34 \mathrm{aC}$ & $51.98 \mathrm{aB}$ & 53.11 \\
A. niger & $33.87 \mathrm{cB}$ & $38.80 \mathrm{bA}$ & $28.41 \mathrm{cC}$ & 33.69 \\
P. lilacinum & $42.98 \mathrm{bA}$ & $18.61 \mathrm{cC}$ & $31.86 \mathrm{bB}$ & 31.15 \\
Mean & 33.71 & 26.69 & 28.06 & \\
\hline
\end{tabular}

Values followed by the same capital letters in the same row or small letters in the same column $(\mathrm{P}=0.01)$ are not significantly different at $\mathrm{P}=0.01$.

The results reported in this study are in agreement with previous findings reported by El-Debaiky (2018), and Fontenelle et al. (2011). These authors reported that the using of several fungi such as Trichoderma spp., Penicillium spp., Aspergillus spp. and Purpureocillium spp. as biological control, agents (BCAs) against the A. solani isolates, revealed that Trichoderma spp. and Aspergillus spp. inhibited the growth of these pathogenic isolates under in vitro and in vivo conditions. Microorganisms reportedly produce toxic substances via antibiosis which are very effective in the inhibition of $A$. solani growth (Leelasuphakul et al., 2008; Matrood \& Rhouma, 2021c). A. niger has the ability to produce cellulase and other enzymes including B-1,3 glucanase, which destroys the glucan found in the A. solani cell wall, a substance which is the main component of the multiple sugars that are involved in the synthesis of the fungal cell wall of Ascomycota (Leelasuphakul et al., 2008).

Polyphenol oxidase (PPO) activity on eggplant leaves treated with two antagonistic fungi at $30 \%$ concentration of stock conidia suspension (as compared with the positive and negative controls) are presented in Figure 1. Statistical analysis revealed a significant difference in PPO activity ( $\mathrm{P}$ $<0.01)$. Data obtained showed that the highest value of 11.98 units/g of soluble protein was recorded for eggplant leaves treated with $A$. niger. However, the lowest activity was found for eggplant leaves treated with $P$. lilacinum (8.11 units/g of soluble protein) $\left(\mathrm{PPO}_{\text {Positive control }}=9.87\right.$ units $/ g$ of soluble protein; $\mathrm{PPO}_{\text {Negative control }}=6.12$ units $/ \mathrm{g}$ of soluble protein). El-Tanany et al. (2018) indicated that some BCAs plays an important role in stimulating systemic resistance in plants treated with Trichoderma spp. against A. solani due to increased polyphenol oxidase enzyme activity. Furthermore, increased PPO activity was also reported due to drought stress in Dolichos lablab leaves (D’Souza \& Devaraj, 2011). Ramamoorthy et al. (2002) pointed out that the induction of defence enzymes involved in phenylpropanoid pathway accumulation of phenolics and PR-Proteins (phenylalanine ammonia-lyase, peroxidase and polyphenol oxidase) may have contributed in the blocking of invasion of Fusarium oxysporum f. sp. lycopersici to tomato roots.

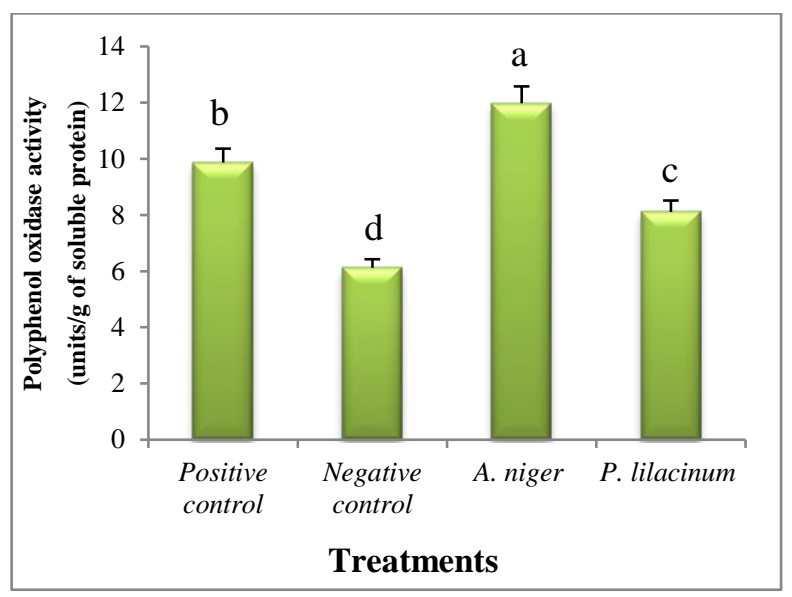

Figure 1. The effect of eggplant leaves treated with fungal antagonists as measured by polyphenol oxidase activity.

A. niger and P. lilacinum applied preventively showed significant effect on eggplant leaves infected with A. solani, and could be recommended for biocontrol. These two soilborne antagonistic fungi allowed not only the protection of plants, but also enhanced the ability to inhibit the mycelial growth of $A$. solani under in vitro conditions. Based on the results of this study, it is concluded that $A$. niger and $P$. Lilacinum isolates used could be employed as foliar treatment to induce Solanaceae systemic resistance, through a specific signal transduction cascade. The systemic resistance induction mechanism of Solanaceae by Aspergillus spp. and Purpureocillium spp. against A. solani is a subject of future research. 


\section{الملخص}

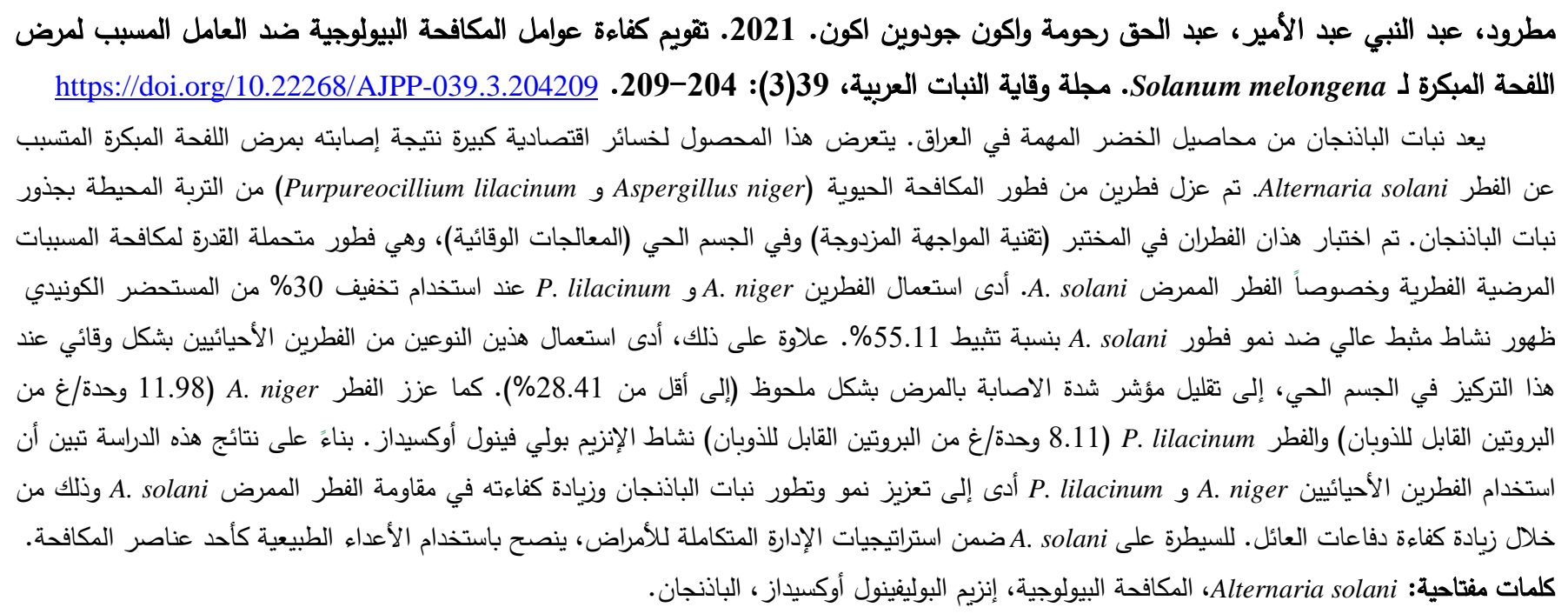

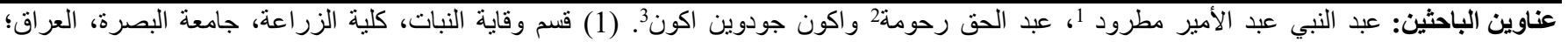

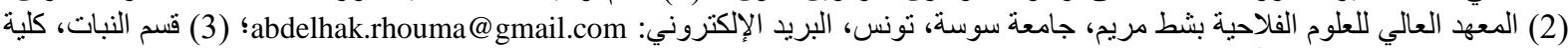

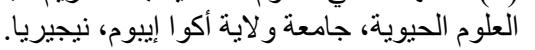

\section{References}

Alsafadi, F., T.A. Al-Fadil and B.A. Trabi. 2012. Evaluation of some local tomato cultivars reaction to early blight disease caused by Alternaria solani. Arab Journal of Plant Protection, 30(1): 139-141.

Atia, M.M.M. 2005. Induction of resistance to Alternaria leaf blight (Alternaria cucumerina) in melon plants by Dl- $\beta$-amino-n-butyric acid. Journal of Environmental Research, 6: 85-104.

Boughalleb-M'Hamdi, N., A. Rhouma, I. Ben Salem and M. M'Hamdi. 2017. Screening and pathogenicity of soil-borne fungal communities in relationship with organically amended soils cultivated by watermelon in Tunisia. Journal of Phytopathology and Pest Management, 4(1): 1-16.

Boughalleb-M'Hamdi, N., I.B. Salem and M. M'Hamdi. 2018. Evaluation of the efficiency of Trichoderma, Penicillium, and Aspergillus species as biological control agents against four soil-borne fungi of melon and watermelon. Egyptian Journal of Biological Pest Control, 28:25. https://doi.org/10.1186/s41938-017-0010-3

D'Souza, M.R. and V.R. Devaraj. 2011. Specific and nonspecific responses of Hyacinth bean (Dolichos lablab) to drought stress. Indian Journal of Biotechnology, 10:130-139.

De Lucca, A. 2007. Harmful fungi in both agriculture and medicine. Revista Iberoamericana de Micología, 24:313. https://doi.org/10.1016/S1130-1406(07)70002-5

El-Debaiky, S.A.E.K. 2018. Effect of the new antagonist; Aspergillus piperis on germination and growth of tomato plant and early blight incidence caused by Alternaria solani. Merit Research Journal of Agricultural Science and Soil Science, 6(4): 41-49.
El-Tanany, M.M., M.A. Hafez, G.A. Ahmed and M.H. Abd El-Mageed. 2018. Efficiency of biotic and abiotic inducers for controlling tomato early blight disease. Middle East Journal of Agriculture Research, 7(2): 650-670.

Esh, A.M.H., M.M.M. Atia and S. Taghian. 2010. Detection of systemic resistance in sugar beet eliciated by non-pathogeenic, phyllosphere-colonizing Bacillus pumilusand B. subtilisagainst the pathogen Cercospora beticolaSaac. Egyptian Journal of Applied Sciences, 25: 340-36.

Fontenelle, A.D.B., S.D. Guzzo, C.M.M. Lucon and R. Harakava. 2011. Growth promotion and induction of resistance in tomato plant against Xanthomonas euvesicatoria and Alternaria solani by Trichoderma spp. Crop Protection, 30(11): 1492-1500. https://doi.org/10.1016/j.cropro.2011.07.019

Gaddeyya, G., P. Shiny Niharika, P. Bharathi and P.K. Ratna Kumar. 2012. Isolation and identification of soil mycoflora in different crop fields at Salur Mandal. Advances in Applied Science Research, 3: 2020-2026.

Leelasuphakul, W., P. Hemmanee and S. Chuenchitt. 2008. Growth inhibitory properties of Bacillus subtilis strains and their metabolites against the green mold pathogen (Penicillium digitatum Sacc.) of citrus fruit. Postharvest Biology and Technology, 48:113-121. https://doi.org/10.1016/j.postharvbio.2007.09.024

Matrood, A.A.A. and A. Rhouma. 2021a. Efficacy of foliar fungicides on controlling early blight disease of eggplant, under laboratory and greenhouse conditions. Novel Research in Microbiology Journal, 5(3): 1283 1293. https://doi.org/10.21608/NRMJ.2021.178310 
Matrood, A.A.A. and A. Rhouma. 2021b. Penicillium and Aspergillus species characterization: Adaptation to environmental factors and sensitivity to aqueous medicinal plants extracts. Review of Plant Studies, 8: $1-11$. https://doi.org/10.18488/journal.69.2021.81.1.11

Matrood, A.A.A. and A. Rhouma. 2021c. Evaluation of the efficiency of Paecilomyces lilacinus and Trichoderma harzianum as biological control agents against Alternaria solani causing early blight disease of eggplant. Pakistan Journal of Phytopathology, 33(1): 171-176.

https://doi.org/10.33866/phytopathol.033.01.0673

Matrood, A.A.A., C.A. Ramírez Valdespino, M.A. AlWaeli, M.I. Khriebaand A. Rhouma. 2021. Pathogenicity and chemical control of Alternaria sp. on date palm (Phoenix dactylifera L.). Plant Science Today, 8:386-391.

Matrood, A.A.A., M.I. Khrieba and O.G. Okon. 2020. Synergistic interaction of Glomus mosseae T. and Trichoderma harzianum $\mathrm{R}$. in the induction of systemic resistance of Cucumis sativus $\mathrm{L}$. to Alternaria alternata (Fr.) K. Plant Science Today, 7(1): 101-108. https://doi.org/10.14719/pst.2020.7.1.629

Mostafa, M.A., M.M. Alawlaqi and N.A. Reyad. 2013. Control of Gardenia leaf spot and bud rot diseases using some natural plant oils. Journal of Microbiology Research, 3(5):185-196.

Onyimba, I.A., C.I.C. Ogbonna, O.O. Chukwu and C.C.E. Odu. 2014. Occurrence of potentially hazardous fungi in exposed brewery spent sorghum grains. European Scientific Journal, 10:449-457.

Poly, S. and D. Srikanta. 2013. Assessment of losses due to early blight (Alternaria solani Ell. And Mart.) and influence of weather factors on disease development in tomato. Journal of Agrometeorology, 15(1): 82-85.

Received: May 26, 2021; Accepted: August 23, 2021
Ramamoorthy, V., T. Raghuchander and R. Samyappan. 2002. Induction of defense related proteins in tomato roots treated with Pseudomonas fluorescens Pf1 and Fusarium oxysporum f.sp. lycopersici. Plant and Soil, 239(1): 55-68. https://doi.org/10.1023/A:1014904815352

Rhouma, A., I. Ben Salem, M. M'Hamdi and N. Boughalleb-M'Hamdi. 2018. Antagonistic potential of certain soilborne fungal bioagents against Monosporascus root rot and vine decline of watermelon and promotion of its growth. Novel Research in Microbiology Journal, 2: 85-100. https://doi.org/10.21608/NRMJ.2018.17864

Rhouma, A., I. Ben Salem, M. M'Hamdi and $N$. Boughalleb-M'Hamdi. 2019. Relationship study among soils physico-chemical properties and Monosporascus cannonballus ascospores densities for cucurbit fields in Tunisia. European Journal of Plant Pathology, 153: 65-78. https://doi.org/10.1007/s10658-018-1541-5

Rhouma, A., I. Ben Salem, N. Boughalleb-M'Hamdi and J.I.R.G. Gomez. 2016. Efficacy of two fungicides for the management of Phytophthora infestans on potato through different applications methods adopted in controlled conditions. International Journal of Applied and Pure Science and Agriculture, 2(12): 3945.

Saeed Omar, A.H. and F.A. Mohammed. 2020. Evaluation of performance of some hybrids of eggplant (Solanum melongena L.) under the influence of adding two types of nutrients. Plant Archives, 20(2): 1009-1016.

Singh, A.K., N. Rai, R.K. Singh, S. Saha and R.K. Rai. 2017. Genetics of resistance to early blight disease in crosses of wild derivatives of tomato. Scientia Horticulturae, 219: 70-78.

Taghian, S., A.M. Esh, A.Z. Aly and M.R.A. Tohamy. 2008. Bacillus subtilis as bioagent used to control cercospora sugar beet leaf spot disease. Journal of Agricultural Research, 35(6): 1347-1360.

تاريخ الاستلام: 2020/5/26؛ تاريخ الموافقة على النشر: 2021/8/23 